EPJ Web of Conferences 68, 00030 (2014)

DOI: $10.1051 /$ epjconf / 20146800030

(c) Owned by the authors, published by EDP Sciences, 2014

\title{
The detection of 4 vital signs of in-patients Using fuzzy database
}

\author{
A Haris Rangkuti, Zulfany Erlisa Rasjid \\ School Of Computer Science, Universitas Bina Nusantara, Jakarta, Indonesia \\ e-mail : rangku2000@binus.ac.id, zulfany@binus.ac.id
}

\begin{abstract}
Actually in order to improve in the performance of the Hospital's administrator, by serve patients effectively and efficiently, the role of information technology become the dominant support. Especially when it comes to patient's conditions, such that it will be reported to a physician as soon as possible, including monitoring the patient's conditions regularly. For this reason it is necessary to have a Hospital Monitoring Information System, that is able to provide information about the patient's condition which is based on the four vital signs, temperature, blood pressure, pulse, and respiration. To monitor the 4 vital signs, the concept of fuzzy logic is used, where the vital signs number approaches 1 then the patient is close to recovery, and on the contrary, when the vital signs number approaches 0 then the patient still has problems. This system also helps nurses to provide answers to the relatives of patients, who wants to know the development of the patient's condition, including the recovery percentage based on the average of Fuzzy max from the 4 vital signs. Using Fuzzy-based monitoring system, the monitoring of the patient's condition becomes simpler and easier.
\end{abstract}

\section{Introduction}

\subsection{Background}

Hospital as a place that serves the society, consists of tasks and activities that demands professionalism and ease of handling services to the patients. Services that are handled in the Hospital consist of first aid, treatment, surgery, healing, and health consultations. Because each and every patient who visited the hospital has different cases, the handling and the procedures are carried out differently in every service and treatment, and also different according to the patient's condition (Adil R,2009; Mustofa Z 2011). The patient's condition can be assessed from several factors: age, sex, disease, vital signs (temperature, blood pressure, pulse, and respiration), medical history and other factors .

To support the performance of the Hospital administrators, serving patients effectively and efficiently, information technology is also used in hospitals. Examples of the use of information technology in hospitals are registration system, medical record, physician's schedule and other hospital facilities that can be accessed via the Internet. This suggests that the use of technology is considered public because each business unit with the help of information technology is able to manage data on their business activities effectively and efficiently, which in turn can yield information that is used as a base to decision making and able to improve services at the hospital.

The patient's condition need to be monitored regularly and the results as well as the patient's complaints regarding the illness need to be communicated to the physician as soon as possible. The Hospital monitoring system in general is not able to provide information to the physician immediately such that it can be handled by the doctor as soon as possible. The solution offered to the hospital to overcome this problem is making use of intranet and internet, allowing information on the patient's condition can be communicated to the doctor as well as the patient's relatives correctly and securely, though especially for relatives, the information need to be communicated through the nurses.

\subsection{Research Objectives}

1. To facilitate nurses to monitor patient's condition based on the 4 vital signs (temperature, blood pressure, pulse and respiration).

2. To facilitate information processing on all patients based on the 4 vital signs.

3. To accelerate the delivery of data from patient's monitor to the physicians who are not in place or to the patient's relatives.

4. Able to obtain accurate information from the Patient Monitoring System efficiently and timely

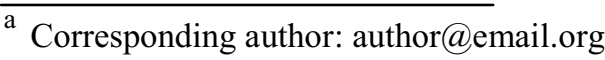


5. To be used as a reference for future researches.

\subsection{Significance of Research}

The significance of this research is:

1. To develop a concept for In-Patient Monitoring System, based on the 4 vital signs using fuzzy database.

2. Accurate and efficient analysis of information that will be provided to the patient's relatives regarding the patient's condition (Percentage of recovery or otherwise)

3. To provide information to the physician regarding the patient's condition such that appropriate action can be instructed by the physician.

4. Producing a better Patient Monitoring System that nurses can rely on and therefore able to provide beter services to the patient's relatives adn physicians.

\subsection{Scope}

The scope of this research is as follows:

1. This research is not only focused on the patient's identity, but also to help visitors and the hospital's staff. This research is focused on the conditions of inpatients.

2. This research is based on the 4 vital signs of inpatients which is temperature, blood pressure, pulse and respiration.

3. This research is developed using the concept of fuzzy logic and include fuzzy database

\subsection{Methodology}

In performing the research on the detection of in-patients using the 4 vital signs, using the common Information Systems Development methods consisting of several stages:

A. Analysis of Patient Data (Patient's condition)

B. Requirement analysis of Patient data

B1. Requirements.of Supporting Fuzzy logic function

B2. Membership 4 vital sign of Fuzzy function

B3. Input and Output

C. Fuzzy of Patient Database Design

$\mathrm{C} 1$. Design input fuzzy query

C2. Design output query

D. Prototype of Patient monitoring using Fuzzy Database

In the figure 1.0 shows the phases of system development monitoring patients being treated in hospital. With this system will facilitate in monitoring the condition of patients who are hospitalized.

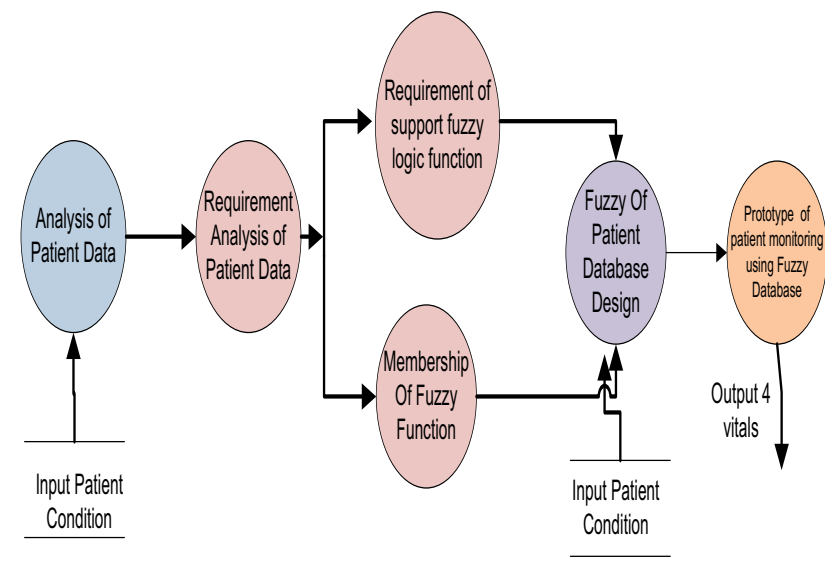

Figure 1.0: Stages in the development of Fuzzy System

\section{Supporting of theory}

\subsection{Fuzzy Sets}

According to the definition of Fuzzy Set (Stuart Russell and Peter Norvig, 2003, P526) Fuzzy set is a condition that states how well an object is satisfied with the answers are not clear / still vague. Fuzzy set is different compared to the usual set / classic. Classic set has clear boundaries regarding the membership of each element on each set. For example: the set of the level of health of patients in a hospital, the food that are exhausted or still intact is part of the set level of health of the patient, where the food exhausted as a condition analogous to 1 and the food still intact analogous to 0 .

What if patients only eat some of the food and therefore has still some food left over? This causes to have this condition partitioned and placed into a new area so that it can be processed. From the analogy an overview of fuzzy set can be obtained. Fuzzy set is an important for fuzzy logic, because fuzzy set is not a method that states all has a fixed value, but it is a method that is able to process existing condition to be analyzed. The unclear statement is the reason that it is called fuzzy (Kusumadewi,2003). In general, conclusions about the sets and fuzzy membership function can be expressed as follows:

a. Fuzzy set emphasize the concept of vague variables ( fuzzy variable) such as seperti variable to represent patient's condition, temperature etc.

b. Fuzzy sets allow partial membership of a set such as the food that is left over expressed as a condition close to finished, but with the level below 1 .

c. Fuzzy membership level in fuzzy set ranges between 0 and 1.

d. Every membership function $\mu$ is associated with a certain fuzzy set and an input value is mapped to the degree of the appropriate membership.

e. All patient data will be stored into the database which is the results of the diagnosis as well as the conclusion resulting from processing system (fuzzy database).

For example, the fuzzy set temperature case has its own membership function, which is $\mu$ heat, which is different to the membership function of the cold fuzzy set $\mu$ cold. For data obtained directly from the patient's condition, 
will be only read by physicians, however the data resulted from the fuzzy set processing will be informed to the patient's relatives. This is preformed to avoid misunderstanding between the patient's relatives and the hospital, as a reason to why the patient still need hospital care. The process can be seen in the following diagram:

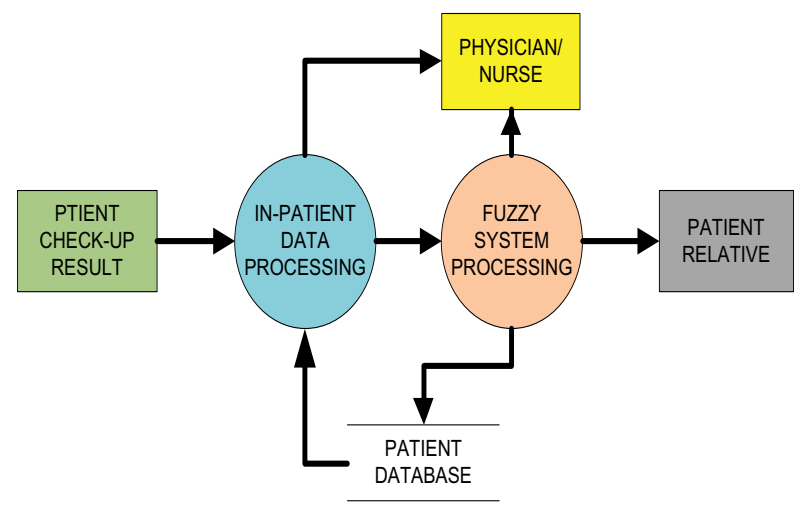

Figure : 2.0 : Information spread from in-patients to physicians and patient's relative.

\subsection{Fuzzy Logic of Membership}

Accoring to (Stuart Russell dan Peter Norvig, 2003, p527) Fuzzy logic itself means a method to provide reasoning using logical expression representing membership in the fuzzy set. The membership for 4 vital signs of in-patients are :

\subsection{Fuzzy Control}

Fuzzy Control is a methodology to develop a control system where the real input and output value parameter is mapped to those represented by fuzzy. Fuzzy control is considered to be successful because of small basic rules, and parameters that can be adapted to increase the system performance. (Stuart Russell dan Peter Norvig, 2003, p527). In general, representation of using the 4 vital signs against dan control can be seen in figure 7.0.

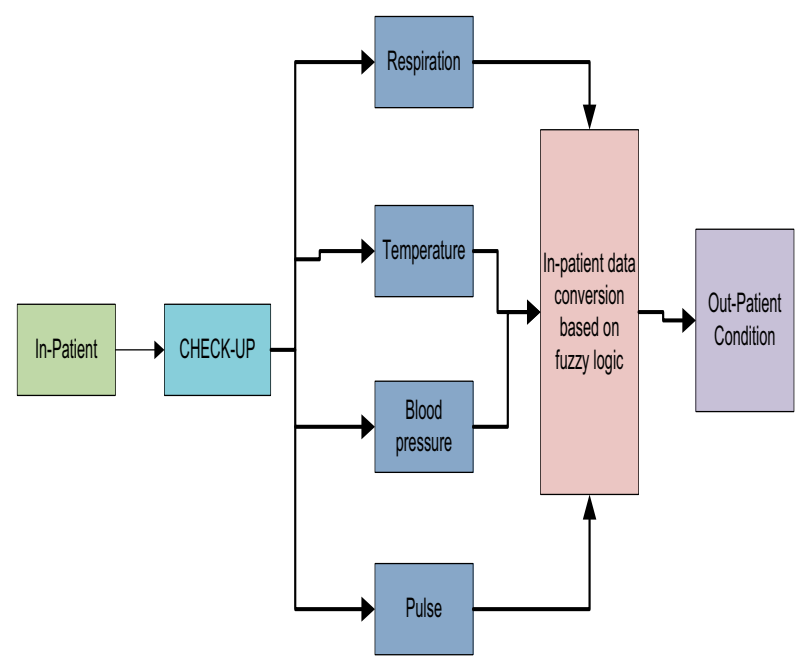

Figure 7.0 : Patient detection based on the 4 vital signs with fuzzy logic and control

\section{RESEARCH METHODOLOGY}

\subsection{Solution to the problem}

In general, the problem is faced when performing inpatient monitoring is:

1. The difficulties to fill in patient condition forms because of unclear understanding of the main variable by looking at the patient.

2. The possiilities of performing incorrect calculation while monitoring the patient.

3. The reports is not sent diectly to the physician therefore incurring a delay while waiting for physician's visit.

4. The missing or damage of important documentation just because that it is kept as hardcopies.

By analysing the problems, the solution discussed in this research is:

By designing the fuzzy logic concept that is integrated in the system to facilitate patient monitoring by either the physician or nurses or even the first physician handling the patient/, which is temperature, blood pressure, pulse and respiration. The existing 4 vital signs that uses fuzzy logic by calculating the average of the 4 factors described above, after which a value between $0-1$ is obtained which is explained below:

$\checkmark$ Approaching $0=$ patient is still ill and

$\checkmark$ Approaching $1=$ patient is getting better or has recovered.

By using this concept, it allows to aid nurses and physicians to assess the patent's condition. For this research, the patient is based on age described as follows:

The variabel age is divided into 4 categories :

Baby, age $<5$ years

Children, $5 \leqslant$ age $<15$ years

Adult, $15 \leqslant$ age $<55$ years

Senior Citizens, age $\geqslant 55$ years

While performing measurements for the vital signs, four variables is needed, where each variable is represented by precentage. Each percentage has its own meaning.

The following is the explains the percentage used in the measurements of the patient's condition:

$$
\begin{array}{lll}
\leqslant 20 \% & & \text { very critical } \\
<20 \leqslant 40 \% & = & \text { Critical } \\
<40 \leqslant 60 \% & = & \text { Ill } \\
<60 \leqslant 80 \% & = & \text { Healthy } \\
<81 \leqslant 100 \% & & =\quad \text { Very Healthy }
\end{array}
$$

In general, the process of patient examination in the sense of developing an in-patient monitoring systembased on fuzzy database with the id of information technology. Generally, this consists of the following steps:

Based on fig. 7.0, it can be seen that the calculation of the patient condition starting with the collection of the 
detection from patient's condition based on the 4 vital signs, followed by the results detected and converted to fuzzy logic numbers/values. More detail steps in the analysis of the patient condition based on the 4 vital signs is as follows:

\subsection{Steps of patient monitoring based on fuzzy control}

Performing reasearch on image selection using the image search based in a database involves 5 steps, all the steps will be seen in fig. 8 (Jefrey L.Whitten, L. D.,2004) :

1. Preparation (collectiion of 4 vital signs of patient data) by nurses

2. Conversion of the 4 vital signs data into fuzzy logic value.

3. Calculating the patient condition as a whole

4. Documenation of the result of the patient's 4 vital signs calculation.

5. The Prototype Development of Patient Monitoring System

The above percentage represents all variables, that is temperature, blood pressure, pulse and respiration.

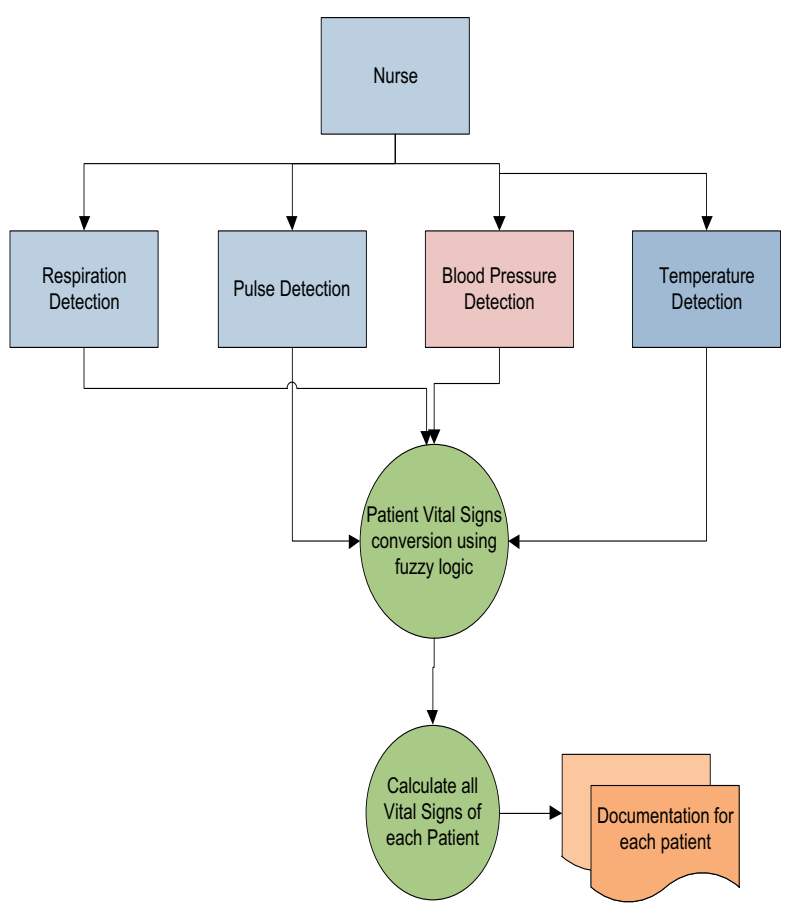

Figure 8.0 : Steps of Patient Monitorng based on fuzzy control (database)

\subsubsection{Preparation step/Data Collection}

The data collection of the patient's 4 vital signs has to be performed carefully and in stages. The data collection must be performed more than once. This is to ensure that all data collected from each patient's 4 vital signs is correct and accurate.

\subsubsection{Conversion of the Result of the Patient's Data Collection Step}

After all Patients 4 vital signs is collected, the next step is to peform conversion of all data that is collected by the nurses into fuzzy logic. Therefore by converting the data, the patients condition can be known as early as possible, for eample, The patient's temperature is $36.8 \mathrm{C}$

$\mu 100 \%[36.8]=(36.8-36) /(37-36)=0.8 / 1=0.8$

Based on the input temperature that was obtained which is $36.8^{\circ}$ the lowest percentage on the left side is $36.8^{\circ}$ is $80 \%$, whereas the highest percentage on the right side of $36.8^{\circ}$ is $100 \%$.

Therefore, condition $=$ lwest percentage + [membership degree $(\mu[\mathrm{x}]) *($ highest percentage - lowest percentage $)]$

$$
\begin{aligned}
& =80 \%+\left(\mu 100 \%[36.8]^{* 20 \%)}\right. \\
& =0.8+(0.8 * 0.2)=0.96 / 96 \% \text { (very healthy) }
\end{aligned}
$$

Therefore the tempersature explains that the patient is very healthy.

However the pulse is 68.5 , so

$$
\begin{gathered}
\begin{array}{c}
\mu 60 \%[68.5]=(68.5-67.5) /(72.5-67.5)=1 / 5=0.2 \\
\text { Condition }=40 \%+(\mu 60 \%[68.5] * 20 \%) \\
=0.4+(0.2 * 0.2)=0.44 / 44 \% \text { (ill) }
\end{array}
\end{gathered}
$$

\subsubsection{Calculating the Patients condition as a whole}

After the each of the patient's 4 vital signs has been converted to fuzzy numbers/values, as a result, the nurses as well as the physicians are able to obtain the condition of the 4 vital signs. This include obtaining details on which vital signs are still problematic. If one of the vital signs are still havig problems, then the nurse/physician can not discharge the patient, except at patient own risk. For example, suppose the use of fuzzy on a patient that is 21 years old, temperatur $36^{\circ} \mathrm{C}$, blood pressure $120 / 60 \mathrm{mmHG}$, pulse $77 /$ minutes, respiration $18 /$ minute, then the conclusion is: temperature condition $=4$, blood pressure condition $=5$, blood pressure condition $=4$, respiration condition $=5$. From the above data (temperature condition, blood pressure condition, pulse condition, respiration condition) the minimum value will be used to represent the patient's condition. The minimum value obtained is 4 , and therefore the patient is healthy.

\subsubsection{The Development of the Prototype of Patient Monitoring System Based on Fuzzy Database}

After ensuring that at each step of monitoring the patient using fuzzy control is completed and already according to the actual condition of the patient, the next step is to develop a prorotype for patient monitoring system. It is expected that the patient monitoring system can facilitate the nurse's job in terms of providing services to the patient and improve the process of providing information to the physician. This application will be developed as a web-based application, therefore the physician is able to monitor the condition at any time and from any location. As for the patient's relative, they would need to actually get the information directly from the ohysician of the nurses, including information wy the patient still need hospial care. The information comes from the condition obtained from the 4 vital signs based 
on fuzzy control. The patient monitoing process includes the steps as can be seen in the following Figure 9:

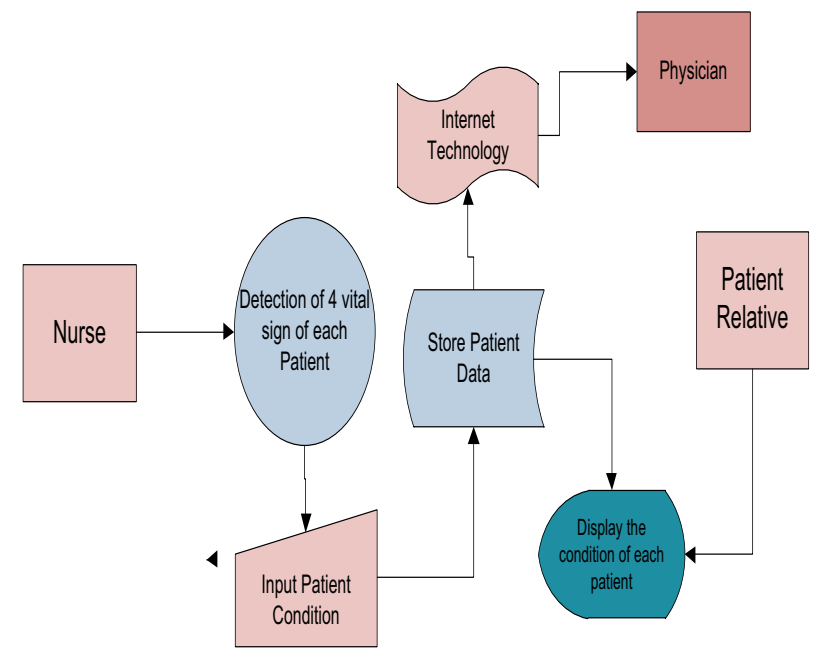

Figure 9.0 Patient Monitoring process by the physician and the patiemt's relatives.

\section{Conclusion and Recommendation}

\subsection{Conclusion}

Based on the research on the requirement of Patient Monitoring System based on fuzzy logic control in a hospital, a conclusion is drawn as folllows:

1. The detection of 4 vital signs of in-patients based on fuzzy database is performed by the Patient Monitoring System becomes computerized and hence facilitate users to access it.

2. Patient Monitoring System based on fuzzy control helps the hospital, especially the nurses and the physicians to monitor the patient's condition at any time and from any location because it can be accessed via the internet (web based).

3. With the existence of the Patient Monitoring System, the patient's conditions are presented in a more complete and accurate frorm and therefore allowing user to obtain information on the patient's condition easily and accyrately.

\subsection{Recommendation}

Based on the research on the requirement of Patient Monitoring System based on fuzzy logic control in a hospital, recomendation is drawn as follows:

1. There is a requirement to have an IT saff in the hospital, responsible to maintain the system and network.

2. There is a requirement tom improve the interface design so that it is more user friendly.

3. The hospital need to keep updating the information on the patient's condition, Physician's schedule that will be displayed by this Patient Monitoring System.

4. The Patient Monitoring System based on fuzzy database helps to reduce human on manual system, which was previously implemented at the hosptal. The Patient Monitoring system facilitate to record the patient's conditions based on the 4 vital signs. (temperature, pulse, blodd pressure and respiration).

5. Hospital admin / user becomes easier by using the Patient Monitoring System, such as updating the data and information.

6. Data becomes more ordered with the use of the Patient Monitoring System.

\section{Reference}

[1] Adil R (2009), Perancangan sistem Monitoring Online pada penderita Jantung Coroner berbasis Identifikasi Sinyal Elevasi, Politeknik Elektronika Negeri Surabaya, Jurnal Tekomnika.

[2] Alan Dix, J. F. (2005). HUMAN-COMPUTER INTERACTION 3r Edition. Upper Saddle River, New Jersey 07458: Pearson Education, Inc.

[3] Jefrey L. Whitten, L. D. (2004). System Analysis \& Design Methods 6 Edition. Avenue of the Americas, New York, NY 10020: Mc-Graw Hill Companies, Inc.

[4] Kusumadewi, S. (2003). Artificial Inteligence (teknik dan applikasinya). Jogjakarta: Graha Ilmu.

[5] Mustofa Z, (2011), Analisis dan Perancangan prototype sistem informasi pemantauan perkembangan kesehatan pasien panti rehabilitasi napza berbasis web dan mobile access, Thesis, UGM

[6] Pressman, R. S. (2005). SOFTWARE ENGINEERING A Practitioner's Approach $6^{\text {th }}$ Edition. Avenue of the Americas, New York, NY 10020: McGraw-Hill Companies, Inc.

[7] Sheiderman, B. (1998). Designing the User Interface Strategies for Effective $3^{\text {rd }}$ Edition. Addison Wesley Longman, Inc.

[8] Stuart Russell, P. N. (2003). Artificial Intelligence A Modern Approach $2^{\text {nd }}$ Edition. Upper Saddle River, New Jersey 07458: Pearson Education, Inc.

[9] Tanebaum, A. S. (2003). Computer Networks $4^{\text {th }}$ Edition. Upper Saddle River, New Jersey 07458: Prentice Hall PTR.

[10] Thomas Connolly, C. B. (2005). DATABASE SYSTEMS. England Pearson Education, Inc.

[11] Vaughan, T. (2004). Multimedia: Making It Work $6^{\text {th }}$ Edition. 1333 Burr Ridge Parkway, Burr Ridge, IL 60527: McGraw-Hill Companies, Inc.

[12] Hofstetter, F. T. (2001). Multimedia Literacy $3^{\text {th }}$ Edition. 1221 Avenue of The Americas, New York, NY, 10020: McGraw-Hill Companies, Inc 